\title{
TECHNOLOGY, AGGLOMERATION, AND REGIONAL COMPETITION FOR INVESTMENT
}

\author{
Bruce A. Blonigen \\ Van Kolpin \\ Working Paper 8862 \\ http://www.nber.org/papers/w8862 \\ NATIONAL BUREAU OF ECONOMIC RESEARCH \\ 1050 Massachusetts Avenue \\ Cambridge, MA 02138 \\ April 2002
}

We thank Ron Davies, Edward Glaeser, and Larry Samuelson for their helpful comments and encouragement. The views expressed herein are those of the authors and not necessarily those of the National Bureau of Economic Research.

(C) 2002 by Bruce A. Blonigen and Van Kolpin. All rights reserved. Short sections of text, not to exceed two paragraphs, may be quoted without explicit permission provided that full credit, including (C notice, is given to the source. 
Technology, Agglomeration, and Regional Competition for Investment Bruce A. Blonigen and Van Kolpin

NBER Working Paper No. 8862

April 2002

JEL No. H71, L23, F23, O31

\begin{abstract}
The active "courting" of firms by municipalities, regions, and even nations has a long-standing history and the competition for firm location through a wide variety of incentives seems to have escalated to new heights in recent years. We develop a model that explores technology development by firms that face regional competition for their investment and examine the endogenous determination of regions' policies, firm technology, and agglomeration externalities. In particular, we find that regional competition leads firms to inefficiently distort their research and development efforts in hopes of improving their standing in the competition amongst regions for their investment. This loss in efficiency is aggravated by the agglomeration externalities that are inherently present in many industries. We offer several case studies that provide evidence consistent with our theoretical conclusions.
\end{abstract}

Bruce A. Blonigen

University of Oregon

Department of Economics

1285 University of Oregon

Eugene, OR 97403-1285

and NBER

$541-346-4680$

bruceb@oregon.uoregon.edu
Van Kolpin

University of Oregon

Department of Economics

1285 University of Oregon

Eugene, OR 97403-1285

541-346-3011

vkolpin@oregon.uoregon.edu 


\section{Introduction.}

In the mid-1990s Caterpillar closed a large plant in Pennsylvania and split its production into four new smaller plants in Mississippi, North Carolina, Kentucky, and South Carolina. According to published reports on the case, the move was precipitated by Caterpillar's desire to take advantage of substantial tax-relief incentives that had been extended. ${ }^{1}$ The fore-mentioned Southern states had been offering incentives to Caterpillar for some time, yet Caterpillar had been reluctant to relocate because the relatively small pool of skilled machinists in these states was apparently deemed insufficient to support a "standard issue" Caterpillar plant. This fact notwithstanding, Caterpillar was eventually able to revise its production process into smaller operations that could be dispersed across these four separate locations.

Previous economic literature has examined a number of issues connected with regional competition for investment - most notably, whether competition among regions promotes or impedes efficient location of production. However, the above example points to issues that have largely been ignored. First, agglomeration externalities may be quite important in firms' location decisions and there has been almost no previous analysis of the interaction between these externalities and regional competition for investment. Clearly, such agglomeration externalities can be an important element in regional competition for investment, as they lower costs for firms, but also entrench them in certain locations. This makes it more difficult for other locations to attract these firms and possibly makes them less able to garner tax incentives. ${ }^{2}$ Despite this, the Caterpillar example above is one where a firm is clearly choosing location and production techniques that weaken agglomeration externalities. Second, despite typical implicit

\footnotetext{
${ }^{1}$ Caterpillar was also involved in protracted disputes with its unionized labor force in the northern U.S. states and the "right-to-work" provisions in southern states were also likely part of their attraction to relocation possibilities. ${ }^{2}$ On the other hand, if agglomeration externalities accompany firms when they relocate, they may be even more prized by competing regions.
} 
assumptions, the production technologies that firms ultimately develop may themselves be endogenously determined by the regional competition for investment process. In particular, the desire of firms to elicit favorable tax concessions may substantially impact the trajectory of technical progress. As we shall show, this link between regional competition and technical innovation may induce inefficient behavior that is in turn compounded by the agglomeration externalities that are often inherent to industrial development.

In this paper, we introduce endogenously determined technical innovation and agglomeration externalities into a model of regional competition for investment. We first present a benchmark model of regional competition in which agglomeration externalities are present and firms' productive capabilities are specified exogenously. Firms choose production plans (given their fixed capabilities) and their location to maximize profits, while regions choose tax packages to maximize a region's welfare. In such a world, we show that competition leads to Pareto efficient location and production decisions by the firm. This result obtains despite the possibility of agglomeration externalities. In fact, it is the regional competition that allows regions to internalize the agglomeration externalities through the tax incentives they offer that is crucial for an efficient outcome in the presence of such externalities.

We then relax the assumption of exogenously specified technology and allow firms to carry out research and development (R\&D) in a step prior to regional competition for their investment. The ability for firms to observably alter their productive capabilities proves to be far from innocuous. Indeed, we show it enables firms to distort the subsequent regional competition and can lead to Pareto inefficient outcomes. The intuition is that firms are able to extract more favorable tax breaks when there is stronger competition amongst regions to secure the firm as a "resident". This provides firms the incentive to choose technologies that do not 
strongly favor one region at the expense of all others, and are generally inferior from an efficiency standpoint. As a result, regional competition can also distort both production and location decisions. Furthermore, these inefficiencies may be exacerbated as a consequence of the fact that firms' inefficient location decisions may lead to weakened agglomeration externalities. In other words, firms may surprisingly choose technologies so that agglomeration externalities are reduced, as Caterpillar did in the mid-1990s. This provides one potential explanation for why Ellison and Glaeser (1997) find less geographic concentration of U.S. manufacturing than one would expect.

These results complement and contrast with previous literature in a number of ways. The natural intuition for many economists is that competition for investments by regions is akin to a prisoner's dilemma as it has little (if any) impact on eventual location decisions, but may nonetheless lead to large transfers of regional tax revenues to the locating firms. Our benchmark model complements this conclusion by showing this result obtains even when accounting for agglomeration externalities, provided firms' production technologies are fixed. This is an important result in the sense that if the firms are owned by domestic shareholders, this competition among regions results in transfers from the regions to the firm's shareholders, but no obvious loss in aggregate welfare for the country as a whole. ${ }^{3}$ The only notable welfare loss is due to resources that may be "wasted" in the bidding process itself.

In fact, a number of previous studies have focused on reasons why competition may actually promote more efficient location of production. Bond and Samuelson (1986) focus on a scenario of asymmetric information, where firms are uncertain ex ante about the productivity of

\footnotetext{
${ }^{3}$ If the firms are foreign-owned then these transfers have more obvious negative welfare implications for the host country bidding for the investment, and this scenario lies behind Graham and Krugman's (1995) recommendation that the U.S. federal government ban state-level incentives directed at attracting foreign direct investment. On the
} 
a particular region, but the region knows its productivity with certainty. In such a scenario, competition for firms facilitates efficient location of firms, as initially offered subsidies (or tax holidays) signal the productivity of the region to the firm. Black and Hoyt (1989) address another inefficiency that may be alleviated by regional competition for investment. Their starting point is that most regions provide public goods and services (such as infrastructure) up to the level that average costs equal average benefits because of standard public finance methods of funding public goods. When the marginal cost of providing public services to a potentially relocating firm are smaller than the tax revenues the firm would yield for additional public services, regions can offer subsidies that reduce the distortion caused by the average cost pricing of public services. Thus, this leads to more efficient location of production across regions. Like Black and Hoyt (1989), Haaparanta (1996) examines two regions competing with subsidies for investment in an environment of perfect information. While most previous studies focused on cost differences between regions, Haaparanta (1996) shows that demand conditions in the region (assuming all or most production is for local consumption) impacts that region's offered subsidies as well. Thus, a high-cost country may attract investment in a competitive environment due to demand conditions. Furthermore, depending on how demand and cost conditions are affected by investment, a subsidy competition between regions may result in different firm location than if there were no such competition. King, McAfee, and Preston (1993) explore a bidding war between two regions for an investment where no participant in the bidding process (either the firms or the regions) know the productivity of the region with certainty until the firm is located, but where subsequent relocation of the firm is possible. The model yields efficient outcomes even when the regions first play a game in infrastructure 
investment (where greater infrastructure yields higher surplus from investment) prior to the bidding process.

In summary, most recent theoretical literature on regional competition for investment has almost exclusively focused on how regional competition may promote efficiency or at least lead to efficient outcomes despite imperfect or asymmetric information on the part of various participants. In contrast, this paper points out that there are potentially serious inefficiencies induced by regional competition that go beyond resources used to participate in the bidding process. These inefficiencies affect firm location, production technique, and the agglomeration externalities that accrue. Perhaps the most closely related literature to ours is work by Eaton and Gersovitz (1984), Brander and Spencer (1987), and Bond and Samuelson (1989). These papers examine a bilateral bargaining process between a firm and a host region and consider the possibility of renegotiation or even unilateral action by the region (such as expropriation) after the firm has located in the region. One general result of these papers is that firms with flexible production techniques will respond by choosing inefficiently less capital-intensive production processes when initially investing in a host region. These papers focus only on a bilateral negotiation between one firm and one region, in contrast to our regional competition model with multiple regions and firms. In addition, they do not consider agglomeration externalities. The only theoretical paper that we have found to consider competition for investment in the presence of agglomeration externalities is Ludema and Wooton (2000). ${ }^{4}$ Their focus is on how exogenous changes in agglomeration affect the intensity of tax competition across regions, whereas ours

\footnotetext{
${ }^{4}$ Head and Ries (1996) and Head, Ries and Swenson (1999) examine the impact of both regional incentives and agglomeration externalities on firm investment decisions in an empirical setting. Both studies find evidence that agglomeration externalities attract investment, while Head and Ries (1996) find that agglomeration externalities enhance the effect of regional incentive policies.
} 
examines how agglomerative forces affect Pareto efficiency of outcomes from regional competition for investment and are endogenously determined by such competition.

A final departure of our paper from previous literature is our use of case study evidence. Previous literature has only provided evidence that regional competition for investments exists and can be intense, whereas our more detailed analyses provide examples of region and firm behavior that is consistent with important assumptions and implications of our model. This seems to be novel in the literature despite the accessible and substantial media accounts of the region-level bidding process for high-profile investments. While case study evidence has wellknown limitations, we feel it is important for the literature to develop models that are demonstrably consistent with cases we observe in reality, rather than create a myriad of theoretical possibilities.

The paper proceeds as follows. Section 2 presents our benchmark model of regional competition in the presence of agglomeration externalities, but with fixed production capabilities of the firm. Section 3 expands the benchmark model to include strategic investment in R\&D and thus allowing for the endogenous determination of technical innovation. Throughout these sections we provide relatively brief case study evidence that is consistent with our model's implications. A final section concludes.

\section{Regional competition for investment: Benchmark model.}

\subsection{Theory.}

This section introduces models of region/firm location games - interactive environments in which regions actively use tax incentives as an inducement for firms to locate within their borders. An important feature of such environments is that the coalescing of firms in a given 
locality may in of itself affect their profitability, i.e., agglomeration externalities may exist. Examples include the resultant influx and training of skilled workers, enhancements to local infrastructure, expansion of supporting service industries, etc. Our analysis demonstrates that equilibrium behavior supports Pareto efficiency even in the presence of agglomeration externalities, provided firms are not actively engaged in research and development. (The case of endogenously determined technical innovation is examined in the following section.)

The decision making agents in our model are composed of a finite set $I$ of firms and a finite set $M$ of regions/municipalities. Each firm must select both a region in which to locate and a production plan to employ. Each region must select a profile of tax incentive packages to offer firms, incentives that may be contingent on both firm location and production decisions. Such contingencies may reflect, for instance, the imposition of zoning restrictions, pollution penalties, hiring quotas, etc.

To formally characterize the action spaces outlined above, we let $X=M$ denote each firm's space of location plans and let $Y$ represent the space of all input employment plans, which we assume to be a closed subset of a finite Euclidean space. Thus $X^{I}=x_{i \in I} X$ and $Y^{I}=x_{i \in I} Y$ represent collective location and production plan spaces respectively. It is also convenient to abuse notation and let $m\left(x^{I}\right)=\left\{i \in I \mid x_{i}=m\right\}$ for each $m \in M$ and $x^{I}=\left(x_{i}\right)_{i \in I} \in X^{I}$. In other words, $m\left(x^{I}\right)$ is the set of all firms selecting region $m$ according to the location choice profile $x^{I}$.

We assume that regions have full flexibility in their tax policy design. Formally, a tax strategy for region $m$ is a mapping $t_{m}: X^{I} \times Y^{I} \rightarrow \Re^{I}$ that specifies in-region firm taxation levels that may be dependent on in-region firm actions but are independent of out-of-region firm actions. Naturally, we shall also assume regions are incapable of taxing firms outside of their jurisdiction. Let $T_{m}$ denote the space of all such tax policies for region $m$ and let $T^{M}=\chi_{m \in M} T_{m}$ 
denote the space of all tax policy profiles. It may also be worth emphasizing that we place no differentiability or continuity constraints on taxation strategies. As a consequence, our general notion of "tax strategy" effectively encompasses any regulatory device that may be used to control firm behavior. For instance, pollution controls may be mimicked by the imposition of large lump sum penalties for discharges in excess of specified standards.

To recap the sequence of play: regions begin by simultaneously announcing their respective taxation policies and firms respond to these announcements by selecting both a region for their home operations and a production plan. A firm strategy is thus a tax-policy-contingent plan-of-action, i.e., a mapping $s: T^{M} \rightarrow X \times Y$. The space of all such mappings is denoted by $S$ and the space of firm strategy profiles is $S^{I}=x_{i \in I} S$. Given a profile of firm and region strategies $s^{I}$ and $t^{M}$ it follows that $t_{m}\left(s^{I}\left(t^{M}\right)\right)_{i}$ represents the tax imposed by region $m$ on firm $i$.

We now turn to a specification of region and firm preferences. Each region $m \in M$ is assumed to be endowed with a real-valued welfare function $\omega_{m}: X^{I} \times Y^{I} \rightarrow \mathfrak{R}$ which is independent of the choices of firms locating outside of region $m$, i.e., if $\left(x^{I}, y^{I}\right)$ represents the collective profile of firm actions, then $\omega_{m}$ is independent of $x_{i}$ and $y_{i}$ whenever $i \notin m\left(x^{I}\right)$. Similarly, each firm $i \in I$ is endowed with a real-valued profit function $\pi_{i}: X^{I} \times Y^{I} \rightarrow \Re$, which we assume is independent of the choices of firms that do not locate in $i$ 's chosen region, i.e., $\pi_{i}$ is independent of $x_{j}$ and $y_{j}$ whenever $x_{j} \neq x_{i}$.

Finally, we assume that both region and firm preferences are quasi-linear in tax payments. Thus, a region's net welfare is the sum of the welfare it receives from realized firm decisions and that it receives from the tax revenues it collects. Similarly, a firm's net profit function is the difference between the profits it receives from realized firm decisions and the tax payment it owes to its home region. Formally, if $\left(s^{I}, t^{M}\right)$ represents a profile of firm and region 
strategies, $m$ and $i$ respectively represent a given region and firm, $H$ represents all firms locating in region $m$ and $n$ is the region in which $i$ chooses to locate, then region $m$ 's net welfare is $\omega_{m}\left(s^{I}\left(t^{M}\right)\right)+\sum_{j \in H} t_{m}\left(s^{I}\left(t^{M}\right)\right)_{j}$ and firm $i$ 's net profit is $\pi_{i}\left(s^{I}\left(t^{M}\right)\right)-t_{n}\left(s^{I}\left(t^{M}\right)\right)_{i}$.

A profile $\left(t^{M *}, s^{I *}\right)$ of region and firm strategies is an equilibrium if no region or firm can benefit from unilaterally altering its strategy. Such a profile is a subgame perfect equilibrium if the firm strategies are in equilibrium on every tax policy subgame. ${ }^{5}$

\section{Theorem 1: Every subgame perfect equilibrium is Pareto efficient.}

Proof: Suppose there exists a subgame perfect equilibrium $\left(t^{M *}, s^{I *}\right)$ which is not Pareto optimal. It follows there must exist a region $m$, a set of firm's $J \subseteq I$, and payoffs $\omega_{m}{ }^{\prime},\left(\pi_{j}{ }^{\prime}\right)_{j \in J}$ that strictly dominate the payoffs these agents would receive from $\left(t^{M *}, s^{I *}\right)$ and which are feasible when the firms in $J$ locate in $m$. Let $\left(y_{j}{ }^{\prime}\right)_{j \in J}$ denote production plans that would support these dominating payoffs. Let $t_{m}{ }^{\prime}$ be a tax policy such that for each $j \in J$, firm $j$ is ensured precisely the payoff $\pi_{j}{ }^{\prime}$, irrespective of the actions of others, as long as $j$ locates in region $m$ and adopts the production plan $y_{j}{ }^{\prime}$. Further assume that $t_{m}{ }^{\prime}$ deters firms in $\mathrm{J}$ from choosing alternative production plans with a threat of high taxes. Likewise, assume firms outside of $J$ are deterred from entering $m$ with a high tax threat. Recall that firm strategies are assumed to be in subgame perfect equilibrium. Thus if $m$ adopts the tax policy $t_{m}{ }^{\prime}$ instead of $t_{m}{ }^{*}$, it follows that precisely the firms in $J$ will locate in region $m$ and they will in turn select the production plans specified by $\left(y_{j}{ }^{\prime}\right)_{j \in J}$. By design, region $m$ will then receive the payoff $\omega_{m}{ }^{\prime}$. We conclude that $t_{m}{ }^{\prime}$ is a strictly

\footnotetext{
${ }^{5}$ Recall that firms observe tax policy prior to making their location/production choices, thus every profile of tax policies effectively determines a distinct subgame within the comprehensive dynamic structure.
} 
better response to $\left(t^{M *}, S^{I *}\right)$ than is $t_{m}{ }^{*}$, contradicting the assumption that $\left(t^{M *}, S^{I *}\right)$ was a subgame perfect equilibrium.

QED

This result reveals that while competition between regions for firms may well induce some reallocation of wealth between firms and regions, equilibrium behavior will nonetheless induce Pareto efficient location and production decisions. Indeed, such competition effectively enables regions to internalize the agglomeration externalities that would otherwise lead to Pareto inefficient firm decisions. The following case study highlights the extent to which regions may design tax policy to internalize externalities and manipulate firm behavior.

\subsection{Case study evidence.}

Begun in 1993, Oregon's Strategic Initiative Program (SIP) was designed to lure large investments to the state by offering up to 15 years of property tax relief for up to $\$ 100$ million of assessed property. Another interesting feature of the program is that participating companies must also make a direct community service payment to the local government equal to 25 percent of the abated amount, not to exceed $\$ 2$ million per year. The negotiated agreements also stipulate employment targets to receive the benefits of the program.

With semiconductor operations in Gresham, Oregon since 1988, Fujitsu Microelectronics was one of the first companies to take advantage of Oregon's SIP program. The community service projects money from Fujitsu's SIP payments went into supporting a variety of programs including a microelectronics training center at a local community college; transportation, childcare, and housing programs for its employees; training of low-income and at-risk workers; and efforts to meet ever-increasing targets on the purchases of local goods and services. 
Obviously, these are all activities that the company would not necessarily have participated in without the stipulations of SIP and some of the activities are ones that extend positive externalities to other firms in the region.

In 1997, with (unexpected) downturn in prices of the current generation of chip Fujitsu was producing, Fujitsu specifically asked the state and local governments for renegotiation of the SIP contract, particularly to the employment targets. As reported by the Portland Oregonian, "Fujitsu said it wanted out of its SIP contract because a downturn in the memory-chip business would prevent it from creating all the 445 jobs promised." (Portland Oregonian, August 22, 1997) After six months, a new agreement was reached with less property tax relief for Fujitsu in exchange for lower employment levels, but continuation of many of the community service payments by Fujitsu.

This case-study clearly demonstrates the efforts of a region to use tax policy as a mechanism to influence factors beyond just the selection of firm location. As in our theoretical model, the state of Oregon has preferences over how firms choose to operate (what services they offer, who they choose to hire, who they choose to purchase from, etc.) as well as where they choose to locate. Moreover, there is a recognition that such factors may create externalities for other firms or workers that may locate in the region and may prove instrumental in additional recruitment efforts. Given that regions do indeed employ such tax policy tools, our benchmark theoretical model would appear to be a reasonable facsimile of the real world - provided that production technology is exogenously specified. We turn to the endogenous determination of technology in the following section.

\section{Competition for investment with endogenous technical innovation.}




\subsection{Theory.}

The benchmark model outlined in previous section does not allow for firms to alter their productive capabilities through investments in research and development (R\&D). In many real world settings, however, the willingness of a firm to relocate may well depend on its ability to effect change in its production alternatives. For instance, current technology may dictate that profits be very dependent on the availability of highly skilled workers, while R\&D efforts may yield new technologies that substantially mitigate this dependence and render firms more geographically mobile. Similarly, the willingness of a region to actively lure a firm may depend on the firm's ability to adopt production methods that are to the region's liking (hire local workers, purchase local goods, pollute minimally, etc.). In this section we enrich our model by formally introducing an R\&D investment stage to the competition for firm investment game. The resulting structure will be referred to as an $R \& D /$ firm location game.

It should be noted that we use the phrases "R\&D" and "technology" in a rather liberal sense. Indeed, $R \& D$ efforts might literally be aimed toward the discovery of a new technical process that improves productive efficiency, as one might traditionally envision. However, efforts to establish political connections and contacts in a region or obtain a clearer understanding for how best to employ region specific resources may also be effective in expanding a firm's production possibilities. For the purposes of our theoretical model, there is no reason to distinguish between the various avenues for expanding production possibilities. Consequently, we shall refer to all such efforts as "R\&D" and refer to the ensuing expansion of production possibilities as improvement in "technology".

We now turn to the formal details of our model. Let us assume that each firm $i \in I$ is endowed with a set $\Theta_{i}$ of investment strategies from which it may select. For each $\theta_{i} \in \Theta_{i}$ let 
$c_{i}\left(\theta_{i}\right)$ denote the cost the firm incurs from this investment strategy. For simplicity, we suppress the effects of risk and uncertainty and assume that R\&D investment leads to certain outcomes regarding technical "know-how" and its effects on firm profit and region welfare functions. Letting $\Gamma$ denote the game outlined in section 1 , this R\&D extension effectively indexes the game by $\theta$ as profit and welfare functions alike are dependent on the state of technology, and thus are in turn dependent on the R\&D strategies pursued by firms. Indeed, different states of technical innovation may lead to different levels of profit and productivity, different levels of agglomeration externalities, different levels of pollution, different levels of local employment, etc. This addition of an R\&D stage transforms our benchmark model into an R\&D/firm location game with the following sequence of play. In stage 0 , firms simultaneously commit to R\&D strategies. These commitments are observable to all firms and all regions in subsequent periods so that choices in these periods may be made contingent on realized $\mathrm{R} \& \mathrm{D}$ decisions. The profile of R\&D strategies $\theta$ generated in stage 0 induces the two stage game $\Gamma(\theta)$, which is identical to the benchmark structure outlined in section 1 except that each firm $i$ 's profits are reduced by $c_{i}\left(\theta_{i}\right)$. In particular, the welfare function of region $m$ is of the form $\omega_{m}(\bullet \mid \theta)$ and profit function of firm $i$ is of the form $\pi_{i}(\bullet \mid \theta)-c_{i}\left(\theta_{i}\right)$. As was the case for production plans, we assume that welfare and profits are independent of the choice of firms locating outside of the relevant region.

One might expect that since Theorem 1 implies that subgame perfect equilibria induce Pareto efficiency on $\Gamma(\theta)$ for each conceivable profile of R\&D strategies $\theta$, it must follow that efficiency will also prevail in the R\&D/firm location game. Such expectations are unfounded.

\section{Theorem 2: Subgame perfect equilibria of the $R \& D /$ firm location game may induce Pareto inefficiency.}


Proof: We demonstrate the validity of our claim by construction. So as not to distract with superfluous complexity, we construct a simple and intuitive example. We emphasize that this simple counter-example should not be interpreted as representative of all $\mathrm{R} \& \mathrm{D} /$ firm location games in which inefficiency prevails as the classes of all such examples are many and varied. Assume that there is a single firm, a single feasible production plan, two R\&D strategies $\theta(1)$ and $\theta(2)$, and two regions competing for the firm's investment. The following table summarizes the cost of these two R\&D strategies as well as the profit and welfare realized when the firm locates in region1 and region2, respectively. Assume that when the firm does not locate in a particular region, that region's welfare is zero.

\begin{tabular}{|c|c|c|c|c|}
\hline & \multicolumn{2}{|c|}{ locate in region1 } & \multicolumn{2}{|c|}{ locate in region 2} \\
\hline$\underline{\operatorname{cost}}$ & firm profit & region1 welfare & firm profit & region 2 welfare \\
\hline$\theta(1): 1$ & 3 & 3 & 0 & 1 \\
\hline$\theta(2): 1$ & 1 & 1 & 1 & 2 \\
\hline
\end{tabular}

The intuition of this example is straightforward. Both R\&D strategies are equally costly, but yield distinct results. The first R\&D strategy takes advantage of features specific to regionl (highly skilled labor, for instance) and is not well suited to locating in region 2 (which may lack highly skilled labor, for instance). The second R\&D strategy generates a production technology that has less peak production/profit potential, but which is more location neutral. Region2 is more "eager" for firm investment, so it values this modest productivity more highly than region1. (One might feel compelled to include both a "status quo" technology and a "comprehensive" technology in which the best of both $\theta(1)$ and $\theta(2)$ are realized. However, if the status quo technology is strictly dominated by the alternatives described, there is nothing lost 
in its omission. Similarly, if the comprehensive technology is prohibitively expensive, it too may be neglected without loss of generality.)

As the reader can readily verify, equilibrium under the $\theta(1)$ - subgame results in the firm locating in region 1, paying 2 units profit in taxes, and earning zero net profit (after R\&D costs and taxes). Equilibrium under the $\theta(2)$ - subgame results in the firm locating in region 2, receiving a subsidy of 1 , and earning a net profit of 1 (after R\&D costs and subsidy). As the firm has the power to select the subgame through its choice of R\&D, it will select the $\theta(2)$-subgame, an inefficient outcome.

The intuition underlying this result is straightforward. Investments in R\&D affect firm profits as well as region welfare, much like firm production plans. However, unlike a production plan that can be location specific, the state of technical innovation affects welfare potential in all regions and the potential profits of all firms. That is, while firms may choose different production plans (different plant designs, different input employment, etc.) at different locations, the constraints imposed by what is technologically feasible apply universally. ${ }^{6}$ Such allencompassing "shadow externalities" affect equilibrium behavior but cannot be internalized by tax policy, implying that inefficiency may inevitably follow.

We note that the proof of Theorem 2 does not rely on inefficiencies resulting from weakened agglomeration externalities, though it is certainly possible to construct such an example. In particular, one could add another firm to the example above and construct an example where regional competition leads to firm location in separate regions, despite positive agglomerative externalities for joint location by the firms in the same region. 
While the constructive example used in the proof of Theorem 2 is a plausible abstraction, we can say something more concrete about the conditions under which we would expect inefficiencies to occur. To do so, we must first construct a formal characterization of the aggregate effects induced by a firm choosing to locate within a particular region. Loosely, the potential impact firm $i$ has in region $m$ will be defined to be the incremental effect of firm $i$ locating in region $m$ as measured by the sum of region welfare and the firm profits generated within the region. In particular, this measure incorporates all effects of agglomeration externalities.

Take as given both the R\&D decisions of all firms and the location and production decisions of all firms except a given firm $i$. We define the potential impact firm $i$ has in a given region $m$ as the largest impact firm $i$ can have in region $m$ under the given circumstances. To be more precise, let SUM1* denote the sum of region $m$ welfare and the sum of all profits earned within region $m$ (including firm $i$ ) when firm $i$ locates in $m$ and chooses production plans which maximize this sum (the plans of all other firms remaining fixed as well as firm $i$ 's R\&D plan). Let SUM2 be defined as equal to the sum of region $m$ welfare and the sum of all profits earned within region $m$ (no longer including firm $i$ ) when firm $i$ locates elsewhere. Then the potential impact of firm $i$ on region $m$ is equal to SUM1* minus SUM2. We further define the $1^{\text {st }}$ best potential impact of firm $i$ as the highest potential impact firm $i$ has amongst all regions. More generally the $r^{\text {th }}$ best potential impact of firm $i$ is iteratively defined as the highest potential impact firm $i$ has amongst all regions outside of those in which the $1^{\text {st }}$ through $(\mathrm{r}-1)^{\text {th }}$ best potential impacts are realized.

\footnotetext{
${ }^{6}$ Of course, quality and quantity of available inputs may differ across regions, so technology constraints may be more confining in some regions than others.
} 
Finally, we define credible equilibria to be those subgame perfect equilibria in which only credible tax incentives are offered by regions, i.e., no region offers a firm incentives that exceed the potential impact the firm can have in the region. Of course incentives that are accepted must be credible even in regular subgame perfect equilibria. Consequently, this added credibility restriction is only binding off of the equilibrium path - incentives that are offered but not accepted. The narrowing of our focus to credible equilibria is, in practical terms, noncontroversial. Indeed, it is unlikely that regions would take the effort to design tax incentives that they would never want accepted.

We now have the machinery to articulate the following important result.

\section{Theorem 3: If an R\&D firm location game is in credible equilibrium then each firm maximizes its $2^{\text {nd }}$ best potential impact given the behavior other firms.}

Proof: We claim that in credible equilibrium the after tax profit earned by the firm must equal the potential impact that firm would have on its second choice region, given its equilibrium $R \& D$ strategy. Indeed, if this after tax profit were less than the noted potential impact, then the second choice region could unilaterally increase its welfare by altering the tax incentives it offers to induce the firm to locate there; contradicting the assumption that firms and regions are in equilibrium. On the other hand, credibility implies that the tax incentives offered by the second choice region cannot exceed the potential impact of the firm in question in the second choice region. As the after tax profit in the first choice region cannot exceed that which would be earned in the second choice region (else the firm's first choice could reduce the incentives it offers and still induce the firm to locate there) the proof of our claim is complete. 
As each firm seeks to maximize its profit and the above paragraph establishes that its profit for each R\&D strategy will equal its corresponding $2^{\text {nd }}$ best potential impact, the firm will invest in $R \& D$ in a manner which maximizes it $2^{\text {nd }}$ best potential impact.

Note that Pareto efficiency requires, given the behavior of others, each firm to select the R\&D strategy that enables it to maximize its $1^{\text {st }}$ best potential impact. Appealing to Theorem 3 , we see that Pareto efficiency can be realized in a credible equilibrium only if for each firm, the same R\&D strategy can be used to maximize its $1^{\text {st }}$ best as well as its $2^{\text {nd }}$ best potential impacts. We argue that such circumstances are relatively implausible. We shall say that a firm's production technology is specialized if the production technique best suited for a particular location and a particular set of agglomerating firms is less suited for alternative circumstances. If the presence of any such specialization is required for efficiency to be realized, then inefficiency can be expected to be the norm in all credible equilibria. This conclusion follows immediately by observing that specialization implies unequal $1^{\text {st }}$ and $2^{\text {nd }}$ best potential impacts and noting that Theorem 3 thus implies inefficiency. Our general result is highlighted with the following Corollary.

\section{Corollary 4: Credible equilibria induce inefficiency whenever efficiency mandates specialized production technology for at least one firm.}

Corollary 4 is particularly important for understanding the role of agglomeration externalities in the inefficiencies caused by regional competition. The development and fine tuning of the production methods for use in localities with strong agglomeration externalities is generally quite different from the efforts that would be pursued if a firm were to instead locate in a region where such externalities are modest or nonexistent. Thus, the very tendency for 
agglomeration externalities to emerge may itself dictate that at least some specialization be present in order to realize Pareto efficiency. In the light of Corollary 4, this fact in turn implies that efficiency cannot be credibly attained in equilibrium.

\subsection{Case study evidence.}

There are a number of cases of U.S. states bidding for investment and subsequent firm location decisions where the facts of the case are arguably consistent with model and results we present in section 3.1 above. We obviously do not observe welfare, profit, and efficiencies under alternative scenarios and, thus, cannot test the model. However, what we do observe in the following cases is evidence of intense regional competition for large investments and a surprisingly strong willingness by firms to substantially alter their production techniques in the process to relocate to regions with obviously lower agglomeration externalities in a number of dimensions.

As mentioned in the introduction, one such case is a plant relocation of the Caterpillar company, maker of construction and materials handling equipment based in Peoria, Illinois. When Caterpillar decided to close its "high-cost" plant in York, Pennsylvania it chose to separate and move production into four smaller sites in separate states in southeastern U.S. states (Mississippi, North Carolina, Kentucky, and South Carolina), where wages were lower. As reported by Aron (1997), this was a long-term strategy by Caterpillar: "While Caterpillar is not moving jobs out of Peoria, the company's expansion is in the South. Due to more limited pools of highly skilled labor, Caterpillar is spreading production among a larger number of smaller, specialized plants." (p. 1036). This suggests an ongoing and concerted effort by Caterpillar to 
devise production methods to make location in areas with lower concentrations of skilled labor feasible, thus resulting in reduced agglomeration benefits in this dimension.

Another example consistent with our model in section 3.1 involves the well-known Mercedes Benz automobile plant location in Alabama in the mid-1990s. There was intense competition for the plant with many states offering very large incentive packages. When Alabama won the bidding war for the Mercedes plant that would begin producing a new model of SUV for sale in the United States, the press and state development experts widely decried the massive incentives provided by Alabama to Mercedes which totaled over $\$ 250$ million and approximately $\$ 160,000$ per job created for a $\$ 300$ million plant. (Indianapolis News, April 1, 1998). A large reason cited for the attractiveness of Alabama was the incentives, $30 \%$ lower pay than in Germany, tradition of hostility toward unions, and access to ports. (Financial Times, October 28, 1993).

However, experts in the field, as well as Mercedes own managers, stressed that Mercedes location in Alabama came with a concomitant change in production process and there are indications that many of these different production processes and "go slow" approach to ramping up production were due to the workforce they were facing in Alabama. For example, Sven Schoolman, a 31-year-old trainer from a plant in Sindelfingen, Germany said: “'In Germany, we don't say we build a car. We say we build a Mercedes. We had to teach that."' (Business Week, March 31, 1997) Similarly, a Washington Post article quoted James E. Harbour, an auto industry consultant, as saying 'It is going to take a long time to bring that plant up to speed, because it is now operating under the most difficult combination of circumstances with everything being allnew." (Washington Post, June 29, 1997) 
In addition, there was evidence of much more permanent changes in production technology and efficiency as the Alabama factory had much less automation than a typical German factory with robots only involved in installing windows. As summarized by Bill Taylor, Vice President of Operations at the plant, "Plant automation was kept simple...We kept the process of building an automobile as simple as possible because we already had all these variables - new product, new people [most of whom are new to the auto industry], new plant... People can only bite off and digest so much at a time." (Industry Week, October 7, 1996).

In summary, these case studies provide evidence that firms made surprisingly substantial modification to their production technology so that a move to a new location could be economically sound. For example, Caterpillar split one plant into four separate plants, and Mercedes eliminated virtually all their robotic automation. Both changes required massive revision of the production process.

These investments also represented locations of firms' plants away from traditional areas with natural agglomerative features, such as a common pool of highly skilled labor and established network of local suppliers, to areas without such features. Thus, these relocations represent dramatic changes that likely reduce agglomeration externalities for these firms (and in the industry in general to some extent).

It's possible that wage (and other cost) differentials alone precipitated these relocations. ${ }^{7}$ However, it is difficult to believe that the aggressive and substantial state incentives offered to these plants did not contribute to the decision by these firms, particularly because of the firm's substantial efforts to alter production processes to fit attributes of the new location. It is also

\footnotetext{
${ }^{7}$ For example, Hanson (1996) provides a model where agglomeration drives up wages in a center region due to congestion, leading firms to relocate production to low-skill, low-wage peripheral regions. Thus, it provides a story of outsourcing certain steps of the production process rather than complete relocation of an integrated production
} 
important to note that inefficient R\&D efforts are likely occurring even if relocation is not taking place. Aron (1997) documents the general tradeoff faced by many industrial machinery firms between Midwest regions rich in skilled labor and low-wage less-skilled Southern regions with aggressive state incentive programs and suggests that many firms have an ongoing evaluation process of alternative locations.

\section{Conclusion.}

While acknowledging that regional competition for investment can be a prisoner's dilemma for the bidding regions, previous literature has found a number of theoretical reasons why regional competition may promote efficient location of production. In contrast, this paper identifies new reasons for why regional competition may lead to inefficient outcomes - such competition may induce the development of inefficient production techniques as well as inefficient firm location and inefficient industry agglomeration. Regional competition gives firms incentives to develop (and potentially adopt) technologies that make alternative locations more competitive. This can allow the firm to extract surplus from regions that exceeds the productive inefficiency costs of developing (and potentially adopting) new technologies. In addition, it may lead to inefficient location of investment with a concomitant lessening of agglomeration externalities. While our results depend on firm production technique flexibility, the case studies illustrate the surprising alterations in production technique that established firms can and will make.

process. Hanson's model does not include regional competition for investments and assumes firms' technologies are fixed. 


\section{References}

Aron, Laurie Joan. "Industrial Machinery: Tale of 2 Regions," Site Selection, Oct./Nov. 1997, pp. 1032-1041.

Black, Dan A. and William H. Hoyt. (1989). "Bidding for Firms," American Economic Review. 79(5):1249-1256.

Bond, Eric W. and Larry Samuelson. (1986) "Tax Holidays as Signals," American Economic Review. 76(3): 820-826.

Bond, Eric W. and Larry Samuelson. (1989) "Bargaining with Commitment, Choice of Techniques, and Direct Foreign Investment," Journal of International Economics. 26: 77-97.

Brander, James, and Barara J. Spencer. (1987) "Foreign Direct Investment with Unemployment and Endogenous Taxes and Tariffs," Journal of International Economics, 22: 257-80.

Davies, Ronald B. (2000) "State Competition for Foreign Direct Investment: A Winnable War?" Mimeo.

Eaton, Jonathan, and M. Gersovitz. (1984) "A Theory for Expropriation and Deviation from Perfect Capital Mobility," Economic Journal, 94: 16-40.

Ellison, Glenn, and Edward L. Glaeser. (1997) "Geographic Concentration in U.S.

Manufacturing Industries: A Dartboard Approach," Journal of Political Economy, Vol. 105(5): 889-927.

Graham, Edward M. and Paul R. Krugman. (1995). Foreign Direct Investment in the United States, Third Edition. Washington, DC: Institute for International Economics.

Haaparanta, Pertti. (1996) "Competition for Foreign Direct Investments," Journal of Public Economics. 63: 141-153.

Hanson, Gordon H. (1996) “Agglomeration, Dispersion, and the Pioneer Firm," Journal of Urban Economics, 39: 255-81.

Head, Keith, and John Ries. (1996) "Inter-City Competition for Foreign Investment: Static and Dynamic Effects of China's Incentive Areas," Journal of Urban Economics, Vol. 40(1): 38-60.

Head, C. Keith, John C. Ries, and Deborah L. Swenson. (1999) "Attracting Foreign Manufacturing: Investment Promotion and Agglomeration," Regional Science and Urban Economics, Vol. 29(2): 197-218.

King, Ian, R. Preston McAfee, and Linda Welling. (1993) "Industrial Blackmail: Dynamic Tax Competition and Public Investment," Canadian Journal of Economics. 26(3): 590-608. 
Ludema, Rodney D. and Ian Wooton. (2000) "Economic Geography and the Fiscal Effects of Regional Integration," Journal of International Economics. 52(2): 331-57. 